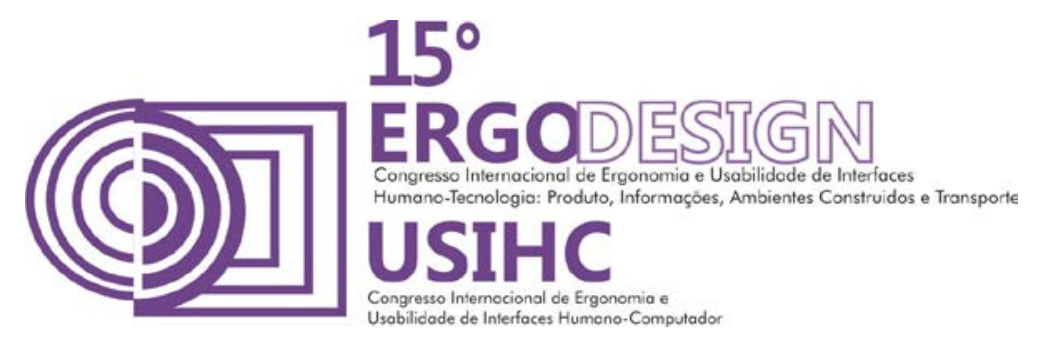

\title{
A ELABORAÇÃO DE DIRETRIZES PROJETUAIS PARA UM LOCAL DE ENTREGA VOLUNTÁRIA A PARTIR DA ANÁLISE ERGONÔMICA
}

\section{THE ELABORATION OF PROJECTIVE GUIDELINES FOR VOLUNTARY DELIVERY SITES FROM THE ERGONOMIC ANALYSIS}

\author{
PEREIRA, Rodrigo Maakaroun (1); \\ CASTRO, lara Sousa (2) \\ RESENDE, Adson Eduardo (3) \\ (1) Universidade do Estado de Minas Gerais, Graduando \\ e-mail: rodrigo.maakaroun@gmail.com \\ (2) Universidade do Estado de Minas Gerais, Doutora \\ e-mail: iarascastro@yahoo.com.br \\ (3) Universidade Federal de Minas Gerais, Doutor \\ e-mail:adson@ufmg.br
}

\begin{abstract}
RESUMO
Os Locais de Entrega Voluntária (LEVs) são constituídos de recipientes colocados em pontos estratégicos, onde o cidadão pode depositar espontaneamente materiais recicláveis destinados à coleta seletiva. Este estudo buscou entender a interação dos usuários com esses equipamentos e suas dificuldades diante da coleta seletiva. A metodologia desse estudo é qualitativa, guiada pela análise ergonômica da atividade. Ela permitiu construir diretrizes que fundamentaram a elaboração de diretrizes para um novo modelo de LEV. Acredita-se que a requalificação dos LEVs poderá motivar a população a participar mais ativamente do processo da coleta seletiva.
\end{abstract}

Palavras-chave: Design, Ergonomia, Coleta Seletiva, Processo projetual

\section{ABSTRACT}

The Voluntary Delivery Sites (VDSs) are made up of containers placed at strategic points where citizens can spontaneously deposit recyclable materials for the selective collection. This study sought to understand the interaction of users with these devices and their difficulties on the selective collection. The methodology of this study is qualitative, guided by ergonomic analysis of activity. She allowed building guidelines that supported the development of guidelines for a new model of VDS. It is believed that the requalification of VDSs can motivate people to participate more actively in the process of selective collection. 


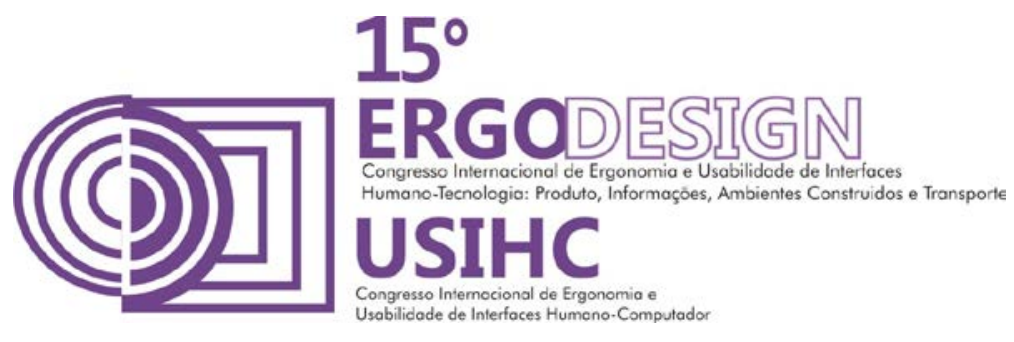

\section{INTRODUÇÃO}

A coleta seletiva pode ser classificada em dois tipos: (a) coleta "porta a porta" realizada por veículos específicos que buscam o material em cada domicílio e (b) coleta "ponto a ponto" realizada pela população que leva os resíduos separados a Locais de Entrega Voluntária (LEVs) (RIBEIRO et al., 2010; PÓLIS, 1998; BEZEN, 2006; VARELLA, 2010).

Os LEVs são recipientes colocados em pontos estratégicos, onde o cidadão pode depositar espontaneamente materiais recicláveis. Os resíduos são recolhidos pela prefeitura ou pelas cooperativas e são direcionados para os galpões de separação (CEMPRE, 2014; BRASIL, 2010; RIBEIRO et al., 2010; PÓLIS, 1998; VARELLA, 2010; BEZEN, 2006).

Existem, atualmente, outras denominações para estes tipos de lugares de coleta voluntária, sendo eles: postos de recebimento ou troca (drop-off sites); Sistemas de Postos de Troca; Ponto Verde e Ponto de Entrega Voluntária (PEVs). Estes dispositivos de coleta, apesar das especificidades funcionais de cada um, apresentam um objetivo em comum, que é armazenar os materiais recicláveis para o seu retorno ao processo produtivo (CEMPRE, 2014; BEZEN, 2006; VARELLA, 2010).

No Brasil, o tipo de coleta seletiva realizada mais comumente é a porta a porta, que se tem mostrado onerosa por exigir gastos elevados com muitos funcionários, equipamentos e com o deslocamento. Por essa razão, a melhor alternativa são os Locais de Entrega Voluntária, pelo fato de iniciar o processo de separação dos materiais a partir da participação da própria comunidade (BRASIL, 2010).

A implantação dos primeiros LEVs em Belo Horizonte ocorreu em 1993. Eles foram instalados em áreas públicas para os cidadãos depositarem materiais recicláveis como plásticos, metais, papéis e papelões previamente separados. Posteriormente, são coletados pelos caminhões da Secretaria de Limpeza Urbana (SLU) e levados para os galpões de triagem da Associação dos Catadores. A expansão da Coleta Seletiva para outras áreas ocorreu com recursos financeiros do Ministério do Meio Ambiente e da Fundação Interamericana.um Muitos LEVs foram espalhados pela cidade, o que gerou mais oportunidades de trabalho na triagem e reciclagem e proporcionou a inclusão de moradores de rua que faziam parte dos programas sociais municipais. (DIAS, 2011; BRASIL, 2010).

O sistema de entrega voluntária em Belo Horizonte é constituído de 91 LEVs em áreas públicas com 435 contêineres. O sucesso dessa coleta seletiva voluntária está diretamente relacionado ao investimento em educação, à sensibilização e à conscientização da sociedade. (CEMPRE, 2014; BRASIL, 2010; VARELLA, 2010; BEZEN, 2006).

Este artigo tem como objetivo compreender a interação dos usuários com os LEVs e suas dificuldades diante da coleta seletiva, a fim de traçar diretrizes para um modelo de projeto futuro.

Percebe-se a necessidade de requalificar esses dispositivos e projetá-los não apenas como recipientes nos quais deverão ser descartados resíduos, mas também como locais de armazenamento de materiais que serão retornados à cadeia de produção. 


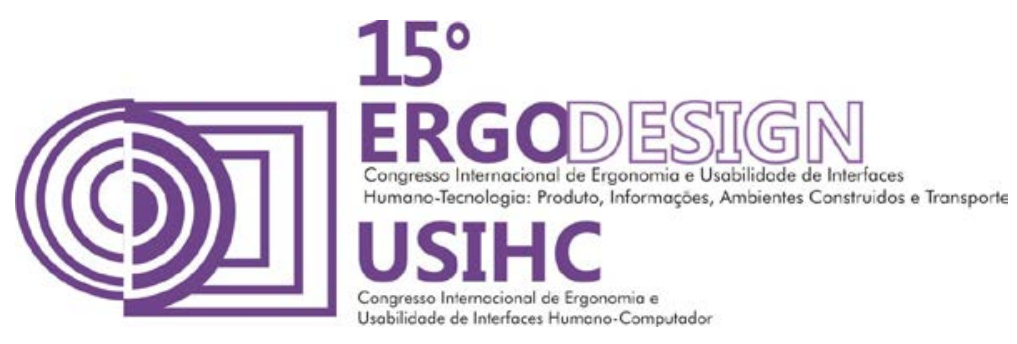

Tal estudo torna-se pertinente pelo fato de que o processo de reciclagem está diretamente associado aos princípios básicos de qualidade de vida do cidadão. Além disso, tais ações possuem caráter inovador, pois focam no projeto de um equipamento existente que ainda não é bem resolvido, além de contribuir efetivamente para o processo integral da coleta seletiva.

\section{METODOLOGIA}

A metodologia adotada neste estudo é qualitativa, de caráter experimental. A pesquisa foi desenvolvida no contexto da região da Pampulha, localizada na zona norte do município de Belo Horizonte. A Pampulha contém 57 LEVs, com sistema de coleta quinzenal e participam da entrega voluntária tanto os moradores da região como pessoas de outras localidades, pois este local concentra grande número de visitantes em virtude da oferta de atividades de lazer e turismo.

Este trabalho foi guiado pela análise da atividade, instrumento da Ergonomia que objetiva analisar exigências e condições reais da atividade (LAVILLE, 1977).

As análises das atividades de entrega voluntária e coleta do material foram realizadas em duas situações distintas: a primeira na região da Pampulha a fim de entender o funcionamento das atividades no contexto urbano e a segunda no Campus da Universidade Federal de Minas Gerais (UFMG) para compreender como as atividades funcionam num contexto menor e em uma situação planejada para o evento Festival de Inverno.

A coleta de dados deste trabalho teve duração de nove meses e foi organizada em cinco etapas que serão explicadas a seguir: (1) análise da atividade de Locais de Entrega Voluntária da região da Pampulha; (2) análise da atividade do sistema experimental de coleta implementado no Festival de Inverno da UFMG; (3) instrumento de Seleção Visual; (4) síntese das diretrizes de projeto; (5) desenvolvimento dos estudos iniciais do modelo.

\subsection{Análise da atividade de locais de entrega voluntária da região da Pampulha}

Nesta etapa foi desenvolvido um estudo de campo em três situações de Locais de Entrega Voluntária. Os participantes desse grupo foram, ao todo, seis estudantes, entre eles alunos e pesquisadores dos cursos de Engenharia de Produção e Engenharia Ambiental da UFMG e do curso de Design de Produto da UEMG. Foram escolhidos três LEVs que permitissem a entrega dos quatros tipos resíduos (plástico, metal, vidro e papel), localizados próximos de pontos de maior movimento da população: um estádio de futebol, um parque de diversão e um parque ecológico. Os pesquisadores organizaram-se em duplas e realizaram observações e verbalizações das atividades de entrega e coleta, abordando os usuários (cidadãos e coletores), durante uma semana. As informações coletadas foram organizadas em relatório técnico parcial para fundamentar as etapas seguintes.

\subsection{Análise da atividade do sistema de coleta implementado no Festival de Inverno da UFMG}

O Festival de Inverno é um evento caracterizado pelo desenvolvimento de novos conceitos e práticas para a sociedade e o meio ambiente e foi promovido, em 2014, no campus da Universidade Federal de Minas Gerais. O evento buscou desenvolver na universidade os 


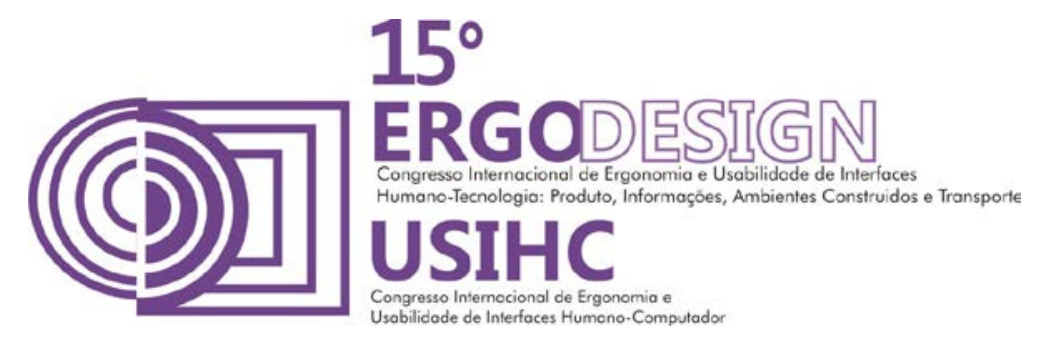

problemas que estão presentes no cotidiano urbano e dentre eles a geração de resíduos. Ele contou com a presença de alunos e pesquisadores engajados no tema, artistas de vários domínios, participantes inscritos nas várias atividades e convidados.

Os pesquisadores deste trabalho apropriaram-se da realização do Festival de Inverno para ser desenvolvida a segunda etapa deste estudo, na qual foram realizadas novas observações das atividades e verbalizações com os usuários durante a interface com equipamentos distintos que constituíram o sistema de coleta seletiva do evento: (a) o LEV existente do Campus que estava localizado em um dos pontos dos principais de acontecimentos do evento, (b) o drive-trhu, localizado no portão de acesso do Campus para facilitar o acesso ao recipiente de descarte de materiais para pessoas que levam o material gerado em suas residências, (c) os LEVs móveis, ou seja, carrinhos motorizados de coleta que foram estacionados temporariamente em locais que tivessem demanda, (d) os tambores para descarte de resíduos orgânicos e resíduos recicláveis gerados nas regiões das confraternizações, (e) o LEV assistido, ou seja, um ponto improvisado com bags para o depósito de todo material reciclável coletado no festival, que ajuda o próprio usuário a fazer o descarte correto a fim de minimizar os esforços na triagem.

O evento constituiu-se um laboratório de situações nas quais os participantes envolvidos no movimento da reciclagem manifestaram de forma muito rica suas criticas aos sistemas experimentais propostos. Este experimento em particular serviu-nos para acelerar a construção de resultados de uma análise da atividade mais longa. Os usuários compartilharam suas experiências vividas no seu engajamento com o tema da coleta seletiva, em cada uma das regiões da cidade em que vivem. A concentração deste tipo de usuário, promovido pelo evento, foi muito positivo no sentido de informar nosso projeto futuro de LEV, diversificando e enriquecendo os dados.

Durante o evento, priorizou-se o recolhimento dos materiais recicláveis e orgânicos, tal como descreve estudo de Burr (2001). Sob sua ótica metodológica, a coleta seletiva é concebida de modo simplificado, a partir de combinações de dois recipientes para separação dos resíduos gerados. Portanto, no Festival de Inverno optou-se pela utilização do agrupamento de dois recipientes, um para armazenar o "Lixo Comum" e um para o "Material Reciclável". Os cinco tipos de equipamentos utilizados no Festival foram alocados aos pares e em pontos estratégicos conforme as atividades diárias do Festival, relacionando-se com o público esperado.

O festival teve a duração de uma semana durante o mês de férias e foram recolhidos $1138 \mathrm{~kg}$ de resíduos: 249 kg de plástico, 624 kg de papel, 209 kg de vidro e 56 kg de metal.

\subsection{Instrumento de Seleção Visual}

Com o objetivo de identificar as preferências, necessidades e aspectos culturais dos usuários, para contemplá-los na formulação de diretrizes projetuais, foi aplicado o método da Seleção Visual, ou "Visual Preferences". Esse termo foi originalmente proposto por Sanoff (1991) e possibilita identificar valores e significados agregados a um conjunto de fatores analisados, sempre que possível relacionando-os a tipos de objetos já encontrados pelos respondentes (RHEINGANTZ et al., 2009).

O método permitiria identificar as características positivas e negativas percebidas pela sociedade em relação à imagem de Locais de Entrega Voluntária já existentes. Esta etapa é 


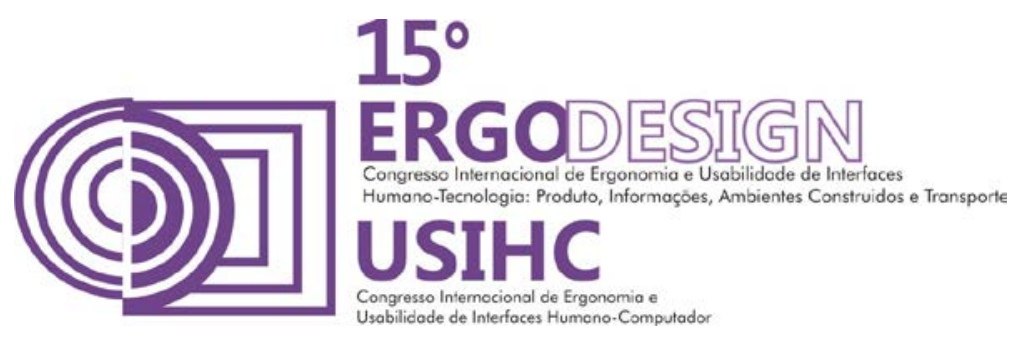

uma das fundamentais para agregar ao projeto futuro do LEV, elementos que permitam ao usuário resignificar o objeto LEV, passando a vê-lo não mais como uma lixeira e sim um sistema de coleta se material para reciclagem. Parte importante de um processo qualificado de reaproveitamento de materiais. Foram selecionados oito tipos de LEVs com características diferentes para apresentar aos participantes. Eles deveriam, apontar os pontos positivos e negativos de cada um dos dispositivos de coleta de acordo com seu ponto de vista. Além disso, o método permitiria caracterizar a população participante.

Foi realizado um teste piloto do método no contexto da Escola de Design da UEMG para verificar o funcionamento da aplicação. Posteriormente, o teste foi aplicado no contexto da Escola de Engenharia da UFMG, com a possibilidade de implementar, futuramente, um protótipo do equipamento projetado a partir das diretrizes que forem traçadas.

As informações coletadas junto aos usuários foram organizadas e quantificadas em tabelas para evidenciar as preferências mais significativas. A duração da coleta de dados dessa etapa foi de três semanas.

\subsection{Síntese das diretrizes de projeto}

Os participantes desta etapa envolveram a equipe de pesquisadores, alunos e professores do programa de extensão "Alternativas de produção em economia solidária: desenvolvimento de sistemas de coleta solidária". Baseado nas informações coletadas com os participantes nas três primeiras etapas da pesquisa,foi possível reuni-las em categorias relativas à estética, à função, à forma e a localização do LEV. Essas categorias foram organizadas em um mapa para possibilitar a visualização e discussões do grupo para elaboração das diretrizes.

\subsection{Desenvolvimento dos estudos iniciais do modelo}

Nesta fase são geradas as possibilidades de solução dos problemas e conceitos. Esse processo pode ser feito através de técnicas para facilitar a produção de ideias como a geração de alternativas em esboços. Estes devem ser apresentados de forma a auxiliar as tomadas de decisões para uma definição de detalhes técnicos e formais do produto (DAPPER 2012).

Segundo Rohleder, Speck e Gómez (2000), o Desenho é uma extensão da capacidade cognitiva do projetista para, principalmente, representar dados, simular o uso e auxiliar na resolução de problemas complexos.

Neste estudo, os modelos são utilizados durante o processo como objeto para discussão da atividade de descarte e coleta e não apenas como apresentação da solução final do modelo.

\section{RESULTADOS}

Baseado na análise ergonômica, foi constatado que existem dificuldades no processo de triagem dos materiais porque os usuários descartam materiais recicláveis nos recipientes de lixo comum e vice-versal. A tipologia do LEV pode contribuir negativamente para a realização de um descarte incorreto. Por exemplo, percebe-se que o usuário nem sempre deposita o material dentro dos recipientes dos LEVs, acumulando os materiais no lado exterior, principalmente papelão, devido ao subdimensionamento do orifício de descarte dos recipientes (FIG. 1). Além 


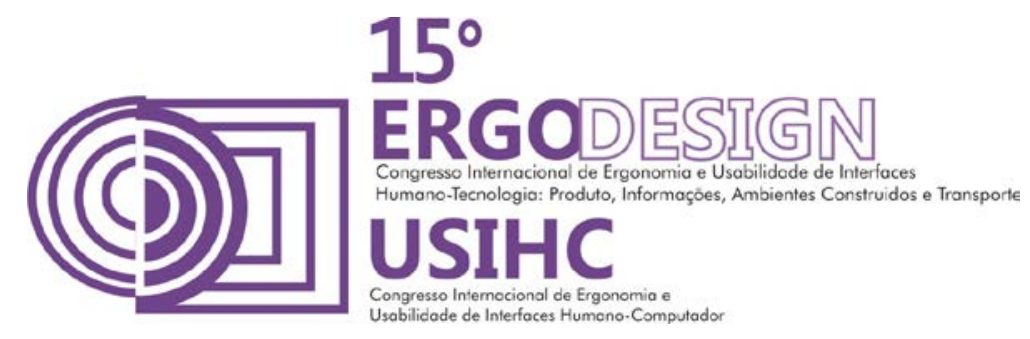

disso, percebe-se também que a altura elevada dos recipientes, muitas vezes, torna-os inacessíveis à população.

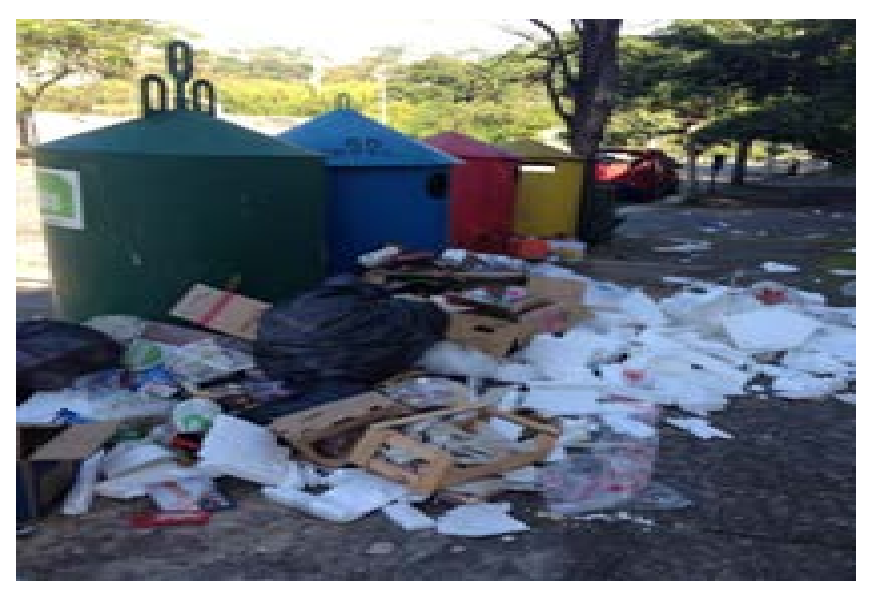

Figura 1: Acúmulo de material depositado no exterior do LEV

Tais achados corroboram com estudo realizado por Varella (2010) e Benzen (2006), os quais identificaram que os problemas que precisam ser superados para a entrega voluntária funcionar são: a) recipientes com altura superior a 1,50 m dificultam o ato de descarte; b) a utilização eficiente do LEV depende da motivação da população e informação sobre os materiais recicláveis; c) um projeto inadequado de um LEV e a escolha incorreta do local para implantá-lo aumentam as chances de uma má utilização do mesmo. podendo ser utilizado como uma lixeira de resíduos comuns. Nesse caso, o objeto é desvalorizado e fica sujeito a atos de vandalismos; d) devido ao subdimensionamento da entrada de materiais em cada recipiente, é comum acumular resíduos na parte externa do LEV, propiciando a sujeira no local e contaminação do solo; e) os resíduos orgânicos, descartados incorretamente no LEV, podem atrair pragas.

Em relação à atividade de coleta realizada pelos garis, constatou-se que algumas situações de trabalho não são ergonômicas. Especificamente quando necessitam de curvar-se dentro dos recipientes e realizar a limpeza com a mão, empurrando todo o material para dentro de uma caixa de papelão ou sacola improvisada (FIG. 2). 

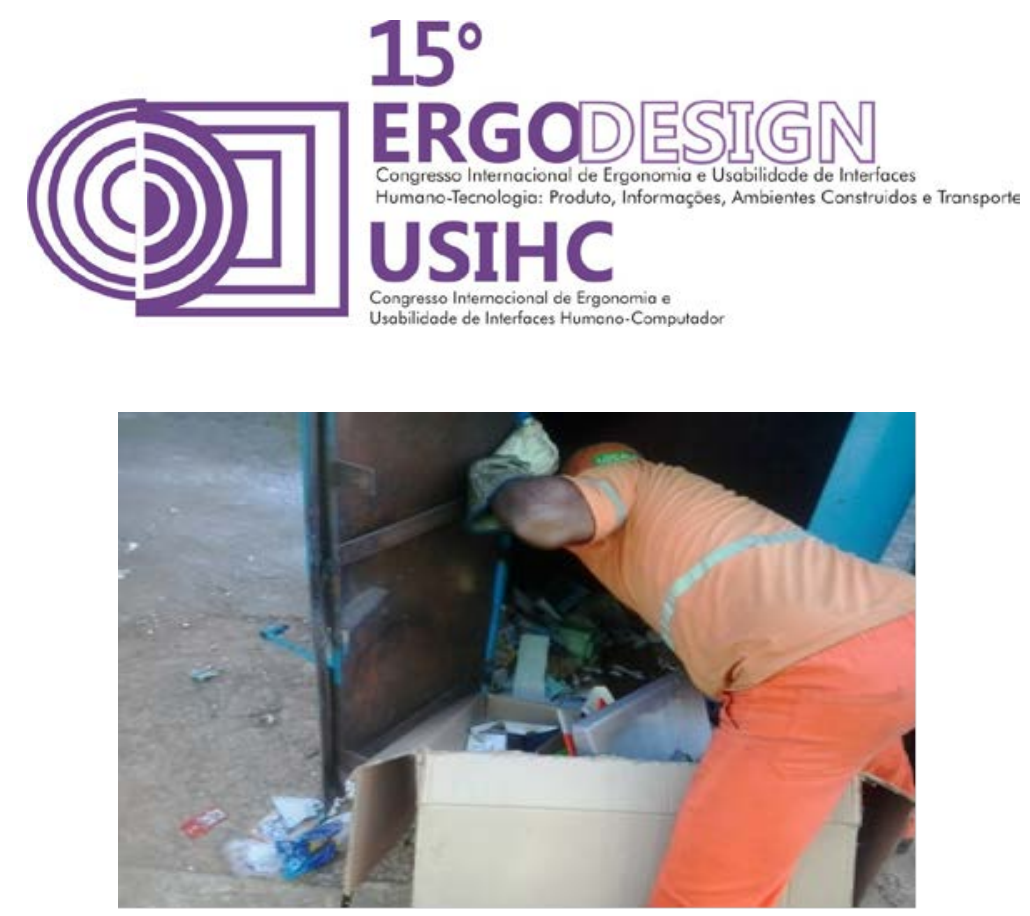

Figura 2: Gari removendo o material do LEV para uma caixa de papelão improvisada.

Tal procedimento ocorre pelo fato de não haver sacolas ou mecanismos internos que agrupem o material para serem transportados até o caminhão, havendo risco de contaminação do usuário, dores musculares, esforço excessivo e demora para realizar a tarefa.

A escolha inadequada do local para a implantação do LEV pode acarretar problemas para a sociedade. Em Lisboa, por exemplo, o sistema de "ponto a ponto", utilizando LEVs, era interessante devido à dificuldade de realizar a coleta de porta a porta em cada edifício pelo caminhão da coleta seletiva. No entanto, este sistema de coleta foi substituído pelo "porta a porta" devido a atos de vandalismo, ao elevado custo de manutenção dos LEVs e à sujeira que acumulada ao seu redor Outro problema detectado era a mistura do resíduo orgânico com os resíduos recicláveis no mesmo recipiente. (VARELLA, 2010).

Sendo assim, é necessário o envolvimento da população através da conscientização por meio de aulas, palestras e em eventos como, por exemplo, o Festival de Inverno realizado na Universidade Federal de Minas Gerais. Nesse evento foi possível observar diferentes tipologias de equipamentos de descarte de resíduos e constatar o bom funcionamento dos mesmos, pois não foram encontrados resíduos descartados no chão. Acredita-se que esse resultado tenha sido fruto da conscientização prévia das pessoas que frequentaram os eventos.

Durante o Festival de Inverno, foi observado, nos eventos noturnos, que o descarte ocorreu algumas vezes de forma incorreta, influenciado pela falta de iluminação artificial perto dos recipientes e também pela semelhança da forma e das dimensões dos coletores.

Os resultados evidenciaram a importância da estética dos recipientes para uma boa efetivação do uso, como a limpeza do entorno, o material de fabricação do objeto e suas cores que podem proporcionara boa aparência e a atratividade do LEV. Também foi constatada a importância da forma do LEV relativa ao dimensionamento dos recipientes, da abertura e dos mecanismo de abertura para ser realizado o descarte, bem como o conforto da atividade realizada pelos usuários.

Portanto, diante dessas constatações, propõem-se diretrizes projetuais para o desenvolvimento de um modelo de um novo LEV, considerando aspectos estéticos, formais e funcionais. 


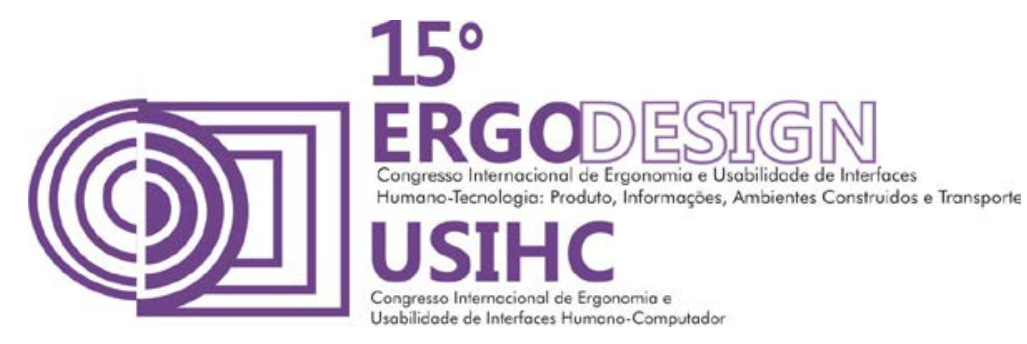

\subsection{Diretrizes relativas aos aspectos estéticos}

(a) Manter as cores da coleta seletiva associada com uma sinalização que possibilite o usuário compreender, assimilar e realizar de maneira correta o descarte, independentemente de sua instrução, idade e cultura;

(b) Utilizar materiais de alta durabilidade, resistência a impactos, estabilidade térmica e impermeabilidade para resistir às intempéries;

(c) Escolher materiais que facilitem a manutenção de limpeza interna e externa dos recipientes

(d) Desenvolver um recipiente atrativo à população para que não passe desapercebido no contexto urbano;

(e) Utilizar materiais reaproveitados e ecológicos que referenciem à coleta seletiva;

(f) Empregar materiais que viabilizem custo de produção e forneçam bons benefícios.

\subsection{Diretrizes relativas aos aspectos formais}

(a) Criar um sistema modular que permita dispor os módulos de diferentes maneiras de acordo com o contexto de implantação e com o volume de descarte de cada material;

(b) Desenvolver módulos com características distintas e adaptadas às particularidades do descarte de cada material reciclável;

(c) Dimensionar o objeto privilegiando sua largura em relação à altura para atender a todos os tipos de usuários e suas limitações: a altura dos recipientes deve estar entre 1,20 m a 1,50 m; a largura e a profundidade devem ser no mínimo de 1,20 m, para que seja possível adaptar um bag internamente. O bag é um tipo de saco de tecido utilizado pelos catadores e garis nas ruas e nos galpões de triagem para acumular e transportar o material reciclável, de modo que sua utilização no LEV facilita o transporte desses materiais. A abertura para o descarte deve ser entre $0,50 \mathrm{~m}$ e 0,80 $\mathrm{m}$ para permitir a inserção de grandes volumes de materiais;

(d) Projetar recipientes com tampa, utilizando um recurso que evite esforço ou uma cobertura externa para proteção contra animais, chuva, vento e pragas;

(f) Evitar o uso de materiais cortantes como lâminas e pontas, que coloquem o usuário em situação de risco de acidente.

\subsection{Diretrizes em relações aos aspectos funcionais}

(a) Projetar o módulo com trava para não permitir que ele fique aberto involuntariamente, mas sem dificultar a abertura e retirada do material pelo gari;

(b) Projetar uma estrutura móvel interna, como um carrinho, para fixar o bag e facilitar a retirada do material pelos garis;

(c) Aproximar o LEV da via de circulação de veículos para que o trajeto e esforço dos garis sejam minimizados durante o transporte do material para o caminhão da coleta seletiva. Se 


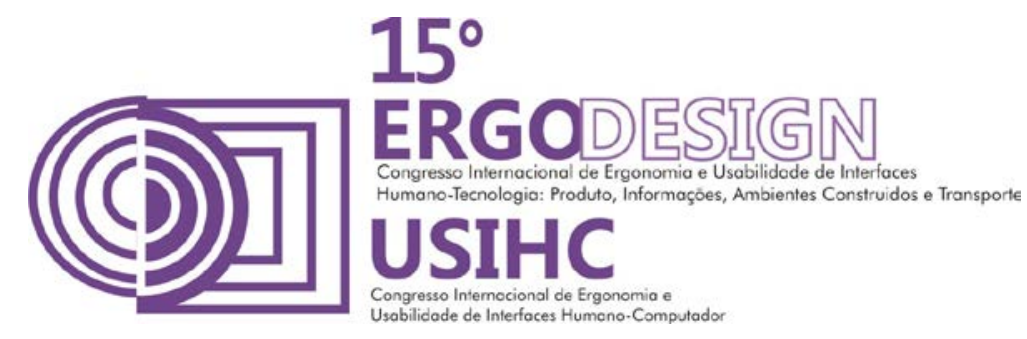

possível, deve existir rampa ou rebaixo na calçada para facilitar a movimentação do carrinho que contém o bag;

(d) Localizar o LEV considerando a acessibilidade do usuários para realizar o descarte, sem prejudicar a movimentação dos transeuntes;

(e) Proporcionar iluminação artificial para aumentar a segurança noturna e auxiliar a atividade de descarte;

(f) Facilitar a liberação do chorume para não acumular líquidos no interior do recipiente, pois danificam os materiais recicláveis e proliferam parasitas, além de causar fetidez;

(g) Interligar o LEV a uma rede de esgoto ou bueiro para destinar o chorume produzido pelo LEV;

(h) Considerar a possibilidade do acesso a uma rede de abastecimento de água para instalar uma torneira para a realização da limpeza do local;

(h) Implantar o LEV buscando harmonizá-lo com o entorno imediato.

\section{CONSIDERAÇÕES FINAIS}

Os LEVs são recipientes importantes no sistema de coleta seletiva e em toda a cadeia da recilcagem. Por ser o elo inicial desta cadeia, a sua ineficiência compromete, indubitavelmente, todo o processo. Devido ao fato de agirem como facilitadores ou não do processo que inclui a entrega do material, descarte, armazenamento e transporte dos materiais recicláveis entregues pela população para a reciclagem nestes pontos de coleta. No entanto, este dispositivo vem sendo mal utilizado No entanto, este dispositivo vem sendo mal utilizado devido a fatores relacionados a sua concepção que desconsidera elementos fundamentais no processo da reciclagem como um todo. Desde a interação com o usuário, aspectos sociais, culturais, informacionais e da própria estrutura do objeto, pois, esta, muitas vezes, não atende as necessidade dos sistemas de coleta e dos vários usuários de um mesmo objeto - o LEV.

A partir deste estudo foi possível analisar o uso destes objetos e elaborar diretrizes relativas aos aspectos estéticos, formais e funcionais que fundamentam a elaboração de um novo modelo de LEV Acredita-se que a requalificação dos LEVs poderá motivar a população a participar mais ativamente do processo da coleta seletiva.

\section{REFÊRENCIAS BIBLIOGRÁFICAS}

BEZEN G. R. Programas Municipais de coleta seletiva em parceria com organizações de catadores na região metropolitana de São Paulo: Desafios e Perspectivas. 2006. Disponível em: <http://www.teses.usp.br/teses/disponiveis/6/6134/tde-24062006-112335/publico/Gina.pdf>. Acesso em: 28 fev. 2014.

BRASIL. Ministério do Meio Ambiente. Manual para implantação de compostagem e de coleta seletiva no âmbito de consórcios públicos. 2010. 69f. Ministério do meio ambiente. Disponível em: <http://www.cidadessustentaveis.org.br/sites/default/files/arquivos/manual de compostagem mma.pdf>. Acesso em: 26 fev. 2014.

BURR, Mark. As Motivações da População de Renda Média na Seleção Doméstica de Materiais Recicláveis do Lixo: um estudo sobre o projeto 'Recic-lar' da Prefeitura do Recife, implementado nos 


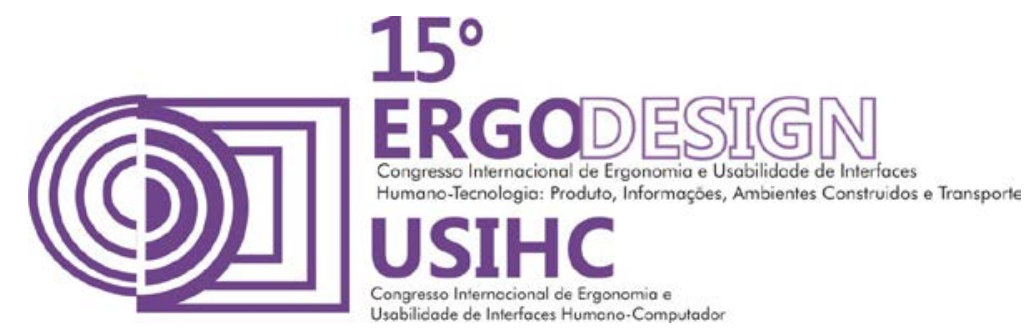

bairros da Torre e Madalena a partir de 12/1999. 2001. 80 f. Dissertação (Mestrado) - Curso de Arquitetura e Urbanismo, Universidade Federal de Pernambuco, Recife, 2001.

CEMPRE. Guia Da Coleta Seletiva. Compromisso Empresarial para Reciclagem. 2014. Disponível em: http://cempre.org.br/download/guia_col_seletiva_2014.pdf. Acesso em: 05 mar. 2014.

DIAS, S. Integração de Trabalhadores Informais na Coleta Seletiva de Recicláveis: o Caso de Belo Horizonte, Brasil. 2011. Belo Horizonte. Disponível em: <http://wiego.org/sites/wiego.org/files/publications/files/Dias_WIEGO_PB4_pt.pdf>. Acesso em: 23 fev. 2014.

LAVILLE, A. Ergonomia. São Paulo: EPU, 1977.

PÓLIS. Coleta seletiva de lixo reciclando materiais, reciclando valores. 1998. Disponível em: <http://www.polis.org.br/uploads/984/984.pdf>. Acesso em: 24 fev. 2014.

RHEINGANTZ, P. A.; AZEVEDO, G. A. N.; BRASILEIRO, A.; ALCÂNTARA, D.; QUEIROZ, M, Observando a Qualidade do Lugar: procedimentos para a avaliação pós-ocupação. Rio de Janeiro: Proarq/FAU/UFRJ 2009.

Disponível em:

http://www.fau.ufrj.br/prolugar/arq_pdf/livros/obs_a_qua_lugar.pdf>. Acesso em: 04 ago. 2014

RIBEIRO H.; GÜNTHER, W.M.R; JACOBI, P.R.; DEMAJOROVIC, J.; BENZEN, G.R., VIVEIROS, M.; OLIVEIRA, M.A.R.; RATHSAM, A.A.; SILVA, F.G.; LUIZ, F.C.S.C.; YUEN, N.T.; PIRES, R.O. Sustentabilidade dos Sistemas Públicos de Saneamento Ambiental na Região Metropolitana de São Paulo. 2010. 167f. Estudos e Pesquisa FUNASA - SP. 2010. Disponível em: $<$ http://www.funasa.gov.br/site/wp-content/files mf/estudosPesquisas ColetaSeletiva.pdf>. Acesso em: 24 fev. 2014.

ROHLEDER, Edison; SPECK, Henderson José; GÓMEZ, Luis Alberto. A importância do desenho no processo de projeto. Abenge: Revista de Ensino de Engenharia, São Paulo, v. 33, n. 2, p.1-30, jul. 2012. Disponível em: <http://www.abenge.org.br/CobengeAnteriores/2000/artigos/026.PDF>. Acesso em: 05 out. 2014.

SANOFF, H. Visual research methods in design. New York: John Wiley \& Sons, INC., 1994.

VARELLA C. V. S. Revirando o lixo: possibilidades e limites da reciclagem como alternativa de tratamento dos resíduos sólidos. 2010.2 Disponível em: $<$ http://www.bibliotecadigital.ufmg.br/dspace/bitstream/handle/1843/BUOS97KK6E/engprodu o cinthiaversianiscottvarella disserta o.pdf?sequence=1>. Acesso em: 23 fev. 2014. 